\title{
Special Announcement
}

\section{World Organisation of Systems and Cybernetics (WOSC) \\ WOSC Eighth International Congress \\ of Cybernetics and Systems \\ (June 11-15, 1990)}

The Eighth WOSC Congress will be held at Hunter College, CUNY, New York (USA), in cooperation with the IEEE. This triennial conference is supported by international groups concerned with management, the sciences, computers, and technology systems. Previous sites for the Congresses have been: London (1969), UK; Oxford (1972), UK; Bucharest (1975), Romania; Amsterdam (1978), The Netherlands; Mexico City (1981), Mexico; Paris (1984), France; and London (1987), UK.

The speakers at the Eighth Congress include computer scientists, mathematicians biologists, sociologists, linguists and scientists. About 300 papers will be presented at various sessions and symposia. In addition to providing a forum for the presentation and discussion of current research, the programme will contain a day-long session featuring speakers who span the history of computing itself. The five-day event will also include a welcoming session, receptions and exhibits.
Special sessions will deal with the following topics:

Biological Cybernetics

Cognitive Science

Self-regulating processes

Fuzzy Systems

Game Playing

Neural Networks

Expert Systems in Software Engineering

Psycho-cybernetics

Socio-cybernetics

\section{Enquiries to}

Professor C. V. Negoita (Congress Chairman) Hunter College, CUNY

695 Park Avenue

New York N.Y. 10021

USA

Tel. (212) 570-5566 